$\mathrm{BNL}-6131 ? 2$

\title{
SURFACE CRYSTALLIZATION AND THIN FILM MELTING IN NORMAL ALKANES
}

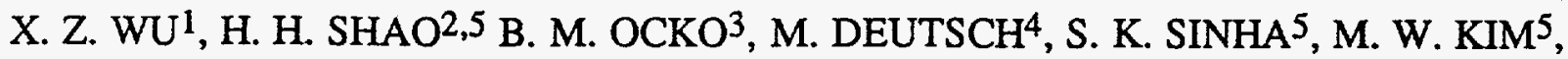 \\ H. E. KING JR. ${ }^{5}$ AND E. B. SIROTA ${ }^{5 *}$ \\ ${ }^{1}$ Physics Dept., Northern Illinois Univ. and Materials Science Div., Argonne Natl. Lab. \\ 2Dept. of Physics, The Ohio State University, Columbus, OH 43210 \\ 3Physics Department, Brookhaven National Laboratory, Upton, NY 11973 \\ ${ }^{4}$ Physics Department, Bar Man University, Ramat Gan 52900, Israel \\ 5 Corporate Research Science Laboratories, Exxon Research and Engineering Co., \\ Route 22 East, Annandale, NJ 08801 \\ *invited speaker
}

\begin{abstract}
Normal alkanes of carbon number $\mathrm{n}>14$ exhibit surface crystallization at their liquid-vapor interface. This has been investigated with $\mathrm{x}$-ray reflectivity, grazing incidence scattering and surface tension measurements. The structure and thermodynamics of the surface layer is consistent with a monolayer of the bulk rotator phase occurring at the surface above the bulk melting temperature. On the other hand, thin films of alkanes on $\mathrm{SiO}_{2}$, exhibit a reduction of the melting temperature. The surface crystalline phase is observed for carbon number $n>14$. The vanishing of surface phase for small $n$ may be due to a transition from surface freezing to surface melting behavior. These measurements can yield the relative surface energies of the various phases.
\end{abstract}

\section{INTRODUCTION}

The normal alkanes $\mathrm{CH}_{3}-\left(\mathrm{CH}_{2}\right)_{(\mathrm{n}-2)}-\mathrm{CH}_{3}$ (abbr. $\mathrm{Cn}$ ) are the most simple organic series and form the basis of lipids, surfactants, liquid-crystals and polymers. The properties of these derivative molecules, both in bulk and at interfaces, are strongly related to the properties of the alkanes. Between the low-temperature highly ordered crystalline phases of the alkanes and their high-temperature liquid phase exist a series of weakly ordered plastic-crystalline phases called the "rotator" phases, because of the lack of long-range order in the rotational degree of freedom of the molecules about their long axes. Some of these intermediate phases have been known and studied for a long time. ${ }^{1-6}$ Recently, the rotator phases have been characterized in detail through $\mathrm{x}$-ray scattering ${ }^{7}$ and calorimetry ${ }^{8}$. Their behavior in mixtures of different carbon numbers ${ }^{9}, 10$ and their response to applied pressure and dissolved gases ${ }^{11}$ have been studied.

Almost all materials exhibit surface melting, as the molecular entropy at the surface is higher than that in the bulk. ${ }^{12,13}$ Liquid crystals, however, aamong the few exceptions: they often exhibit surface induced ordering effects in addition to the disorder associated with reduced dimensionality. This has been demonstrated by various experiments of freely-suspended films. ${ }^{14-19}$ At the free surface of bulk liquid crystals in their isotropic or nematic phase, surface smectic ordering is in general observed. ${ }^{20-23}$ Such ordering has also been studied at the solidliquid interface. ${ }^{24}$ The studies of alkanes. ${ }^{25-28}$ which are much simpler molecules, are a natural extension of the liquid crystal studies which showed that the methyl-group of the alkane chain

To appear in: Dynamics in Small Confining Systems, J.M. Drake, S. M. Troian R. Kopclman ed., MRS Proc. vol. 366 (1995). 
resides at the free surface. The alkane system has also been employed to further the understanding of thermally generated capillary waves, through measurements of the temperature dependence of surface roughness. ${ }^{29-32}$

We will discuss here, (1) the work of Wu et al. ${ }^{25-28}$ in which surface crystallization of a $2 \mathrm{D}$ crystalline layer on a bulk isotropic liquid of $n$-alkanes was studied and (2) the work of Shao et al. ${ }^{33,34}$ where thin films of alkanes on $\mathrm{SiO}_{2}$ substrate were shown to melt at lower temperatures. The surface behavior will be compared to the bulk properties.

The bulk properties of the n-alkanes are extremely rich. There are 5 rotator phases . distinguished by order parameters such as distortion (D), tilt magnitude $(\theta)$ and tilt direction $(\phi) .{ }^{7,8}$ The bulk phase diagram is shown in Fig. 1, plotted with respect to the melting temperature, $T_{\mathrm{m}}$. The highest temperature bulk rotator phases will be the most relevant for the understanding of the surface crystalline phases. For the intermediate chain-lengths studied, it is the one with the highest symmetry (the $\mathrm{R}_{\text {II }}$ phase), in which the molecules are in layers, oriented along the layer normal and packed in an average hexagonal lattice. At lower chain-lengths, the bulk pure alkanes exhibit the $\mathrm{R}_{\mathrm{I}}$ phase which differs from the $\mathrm{R}_{\text {II }}$ phase by a finite distortion of the hexagonal lattice. The transition from $\mathrm{R}_{I}$ to $\mathrm{R}_{\mathrm{II}}$ is first-order. The distortion is strongly related to interlayer coupling, and in binary mixtures ${ }^{9}$ where interlayer coupling is reduced, the highest temperature bulk rotator phase for the short average chain-lengths becomes the $\mathrm{R}_{\mathrm{II}}$ phase. The higher chain-length alkanes ( $n \geq 26$ ) melt from a tilted phase which (for $n \leq 30$ ) is called $R_{I V}$, where the tilt direction is toward next-nearest neighbors. This tilted phase occurs above the $\mathrm{R}_{\mathrm{II}}$ both in chain-length and in temperature and has been attributed ${ }^{8}$ to the chain-end defects which appear in the rotator phases as temperature is raised. 35,36

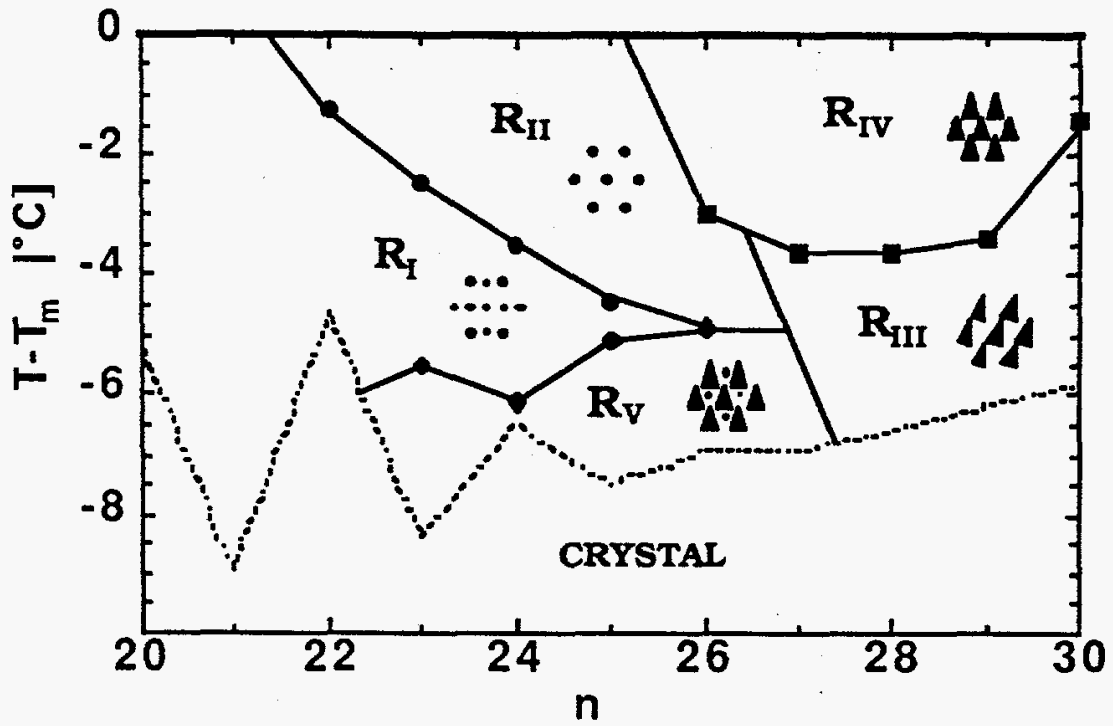

Fig 1. Phase diagram showing the rotator phases of bulk normal alkanes plotted relative to the melting temperature. The structures of the phases are shown schematically. The melting temperature $T_{m}$ is shown in Fig. 8. (from Sirota et al. ${ }^{7,8}$ )

A number of complementary techniques were employed in the study of surface freezing of liquid alkanes. X-ray reflectivity and grazing incidence $\mathrm{X}$-ray scattering GDXS were performed on the Harvard/BNL liquid surface spectrometer at X22B at the N.S.L.S. X-ray reflectivity measures the electron density normal to the surface and can easily determine the thickness of a 


\section{DISCLAIMER}

Portions of this document may be illegible in electronic image products. Images are produced from the best available original document. 
surface layer whose density is different from that of the bulk. GLXS measures the in-plane structure at a surface. Surface tension measurements were performed using the Wilhelmy plate method. The experimental details can be found elsewhere. $25-27$

\section{Liquid Surface: Reflectivity}

Shown in Fig. 2 is the $x$-ray reflectivity in the liquid and surface-crystal phases of $\mathrm{C} 20$, $\mathrm{C} 30$ and $\mathrm{C} 44$. When there is no surface crystal layer, the reflectivity, typical for a liquid surface, is well described by the smooth Fresnel reflectivity modified by surface roughness. The surface roughness has been shown to be due to capillary waves as well as an intrinsic roughness. ${ }^{30-32}$ The surface-crystal layer produces a pronounced modulation of the reflectivity curve. The period of the oscillation yields the thickness of the layer, and a fit to a simple slab model with interface roughness yields the density and interfacial widths. The density profile derived from such a fit is shown in the inset to Fig. 2 . The details of the fitting are described elsewhere. ${ }^{25}$ These surface crystals are thermodynamically stable between the bulk freezing temperature $T_{f}$ and the surface crystallization temperature $T_{s}$, which is as large as $3^{\circ} \mathrm{C}$ higher. The reflectivity profile does not change over that temperature range. That implies that there is no freezing of additional layers as the temperature is lowered towards bulk freezing. There is no layer-by-layer or continuous growth from the surface with decreasing temperature, as was observed in liquid crystals. ${ }^{19,21,22,24}$

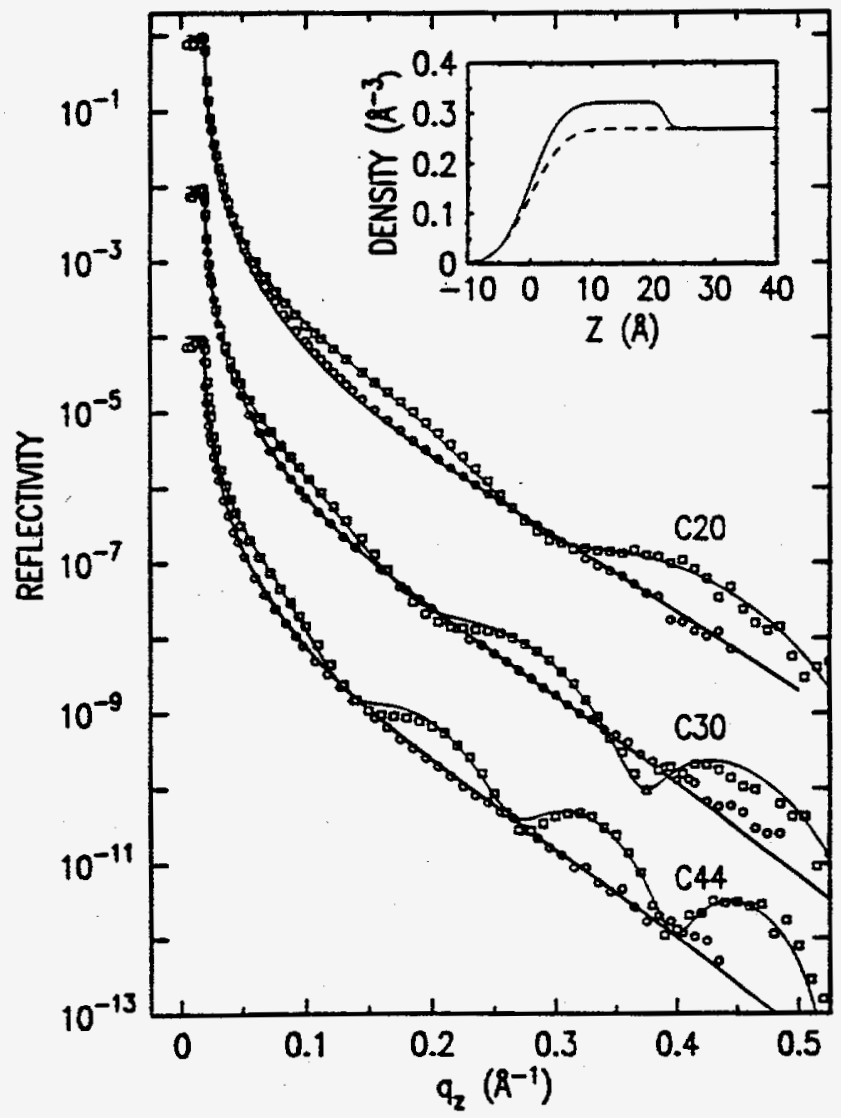

Fig. 2. Reflectivities for $\mathrm{C} 20, \mathrm{C} 30$ and $\mathrm{C} 44$. The data for the liquid surface phase are the dots and for the surface-crystal phase are the squares. The curves are shifted by 2 decades for better visibility. The solid lines are fits to the data using simple density profiles. ${ }^{27}$ (INSERT) The surface density profile for the liquid (dashed) and crystal (solid lines) surface. (from Wu et al. ${ }^{27}$ ) 


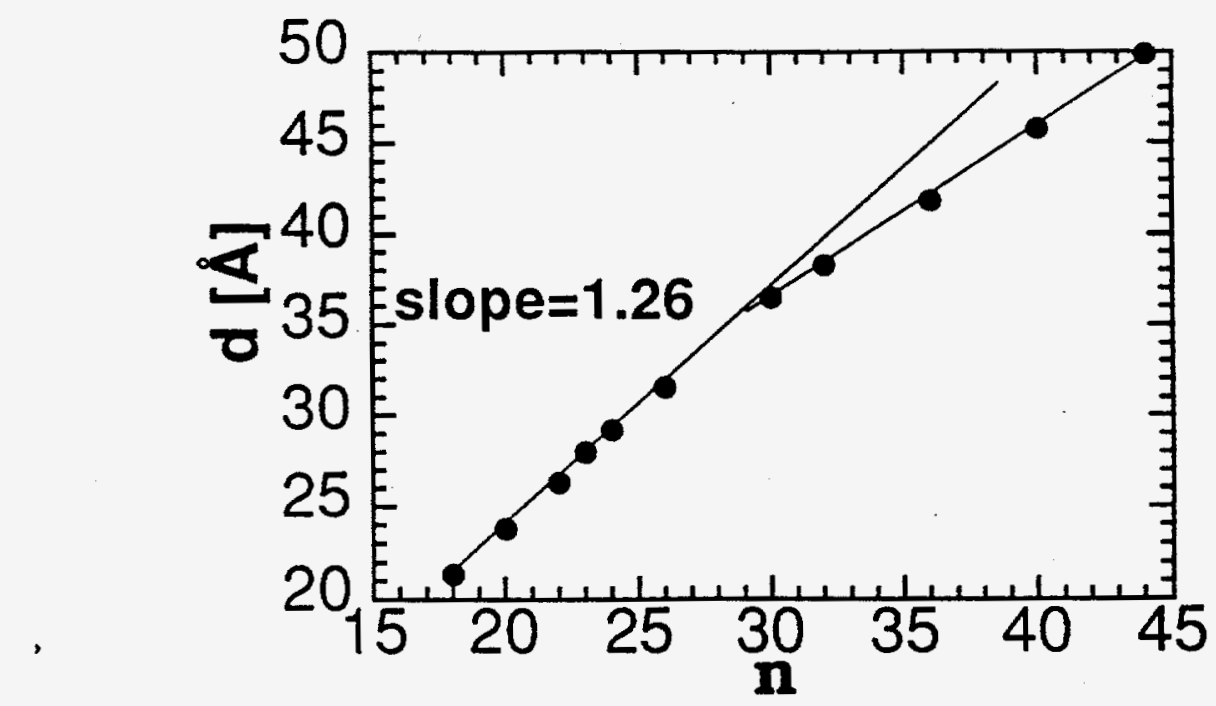

Fig. 3. The thickness of the surface-crystal layer as determined from x-ray reflectivity. (from Wu et al. ${ }^{26}$ )

Shown in Fig. 3 is the surface layer thickness (d) plotted versus chain-length. Below $\mathrm{n} \approx 28, \mathrm{~d}$ increases by about $1.26 \pm 0.02 \AA /$ carbon which is the projected length per carbon along an extended chain. Above $n \approx 28$ the slope is lower, suggesting that the molecules are tilted. We recall that the highest temperature bulk rotator phases are tilted for $n>26$.

\section{Liquid Surface: GIXS}

Shown in Fig. 4(a) is a grazing incidence x-ray scattering (GIXS) in-plane radial scan exhibiting a sharp peak at $\mathrm{q} \approx 1.52 \AA^{-1}$ in the surface-crystal phase of $C 20$. The single peak at this position is characteristic of the hexagonal packing observed in the $\mathrm{R}_{\mathrm{II}}$ rotator phase. A sample rotation scan of the liquid surface with the in-plane q vector kept fixed at the peak position is shown in Fig. 4(b). Peaks separated by $60^{\circ}$ suggest that the structure is hexagonal and that the domain size is comparable to the surface area probed which is of order millimeters. Thus the horizontal-to-vertical dimensional ratio of this surface crystal is enormous; of order $10^{6}$ or more.

To confirm whether or not the molecules are tilted, and to measure the tilt direction, surface-normal "rod scans" were performed at the in-plane peak positions. ${ }^{27}$ These confirmed that the molecules are untilted for $n<28$ and tilted toward nearest neighbors for $n>28$. Note that this tilt direction is different from the $\mathrm{R}_{\mathrm{IV}}$ bulk rotator phase which exhibits a tilt toward the nextnearest neighbor. We note that the surface crystalline temperatures are always above those of the bulk rotator phase, and generally, when both tilt directions occur, the nearest-neighbor tilt occurs at higher temperature. ${ }^{37,38}$ If bulk crystallization had not limited the temperature range of stability of the surface phase, a transition to next-nearest neighbor tilt might be expected at lower temperature. Such transitions were indeed observed very recently in surface crystalline layers of binary alkane mixtures. 39 

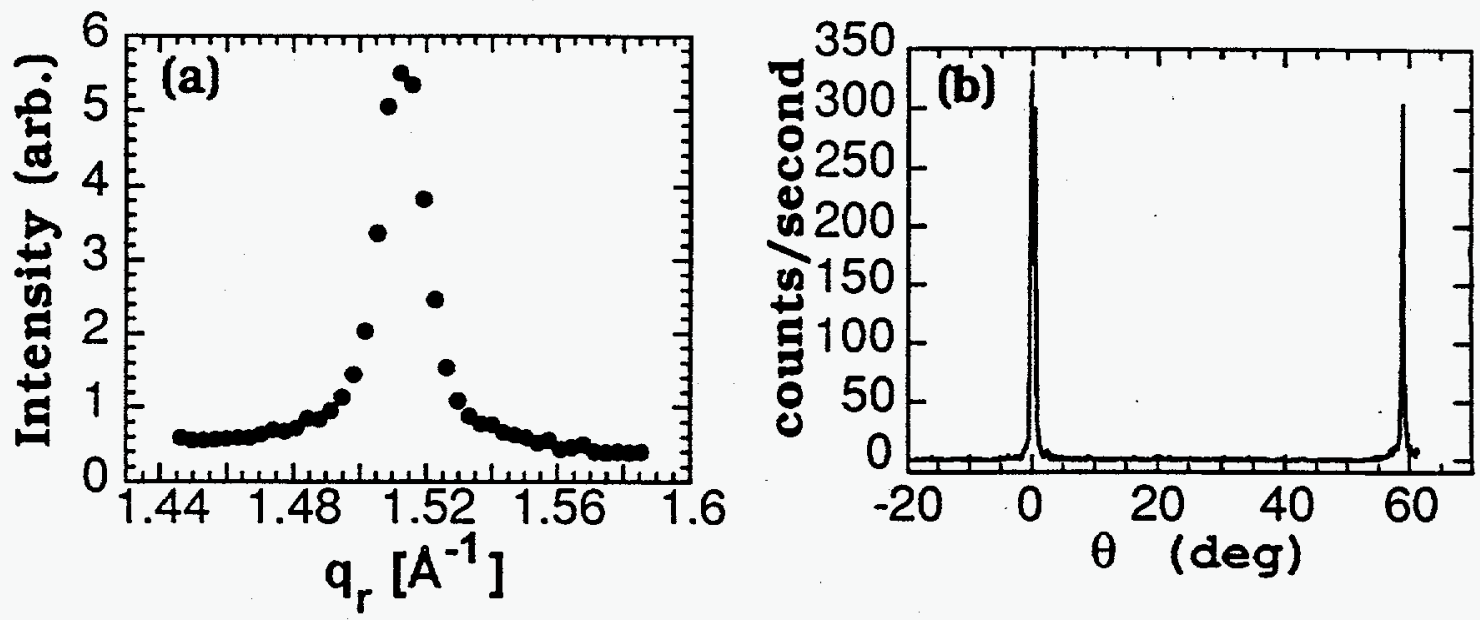

Fig. 4. (a) In-plane radial scans of $\mathrm{C} 20$ in the surface crystalline phase. (from Wu et $\mathrm{al}^{25}$ ) (b) Sample rotation scan in the hexagonal surface-crystalline phase of C20. Note the peaks occur close to a $60^{\circ}$ interval, as expected for hexagonal packing.

Shown in Fig. 5 is the spacing associated with the in-plane peak at $\mathrm{q}_{\mathrm{z}}=0$. The increase in spacing at $n=30$ corresponds to the onset of tilt (Fig. 3), however, since the tilt direction is toward a nearest neighbor, this spacing would not be directly affected merely by a tilt of cylinders. The increased spacing for longer chain lengths must then be related to the increasing importance of chain-end conformational disorder as $\mathrm{n}$ and $\mathrm{T}$ increase, ${ }^{28}$ which itself is believed to be the cause of the tilt.

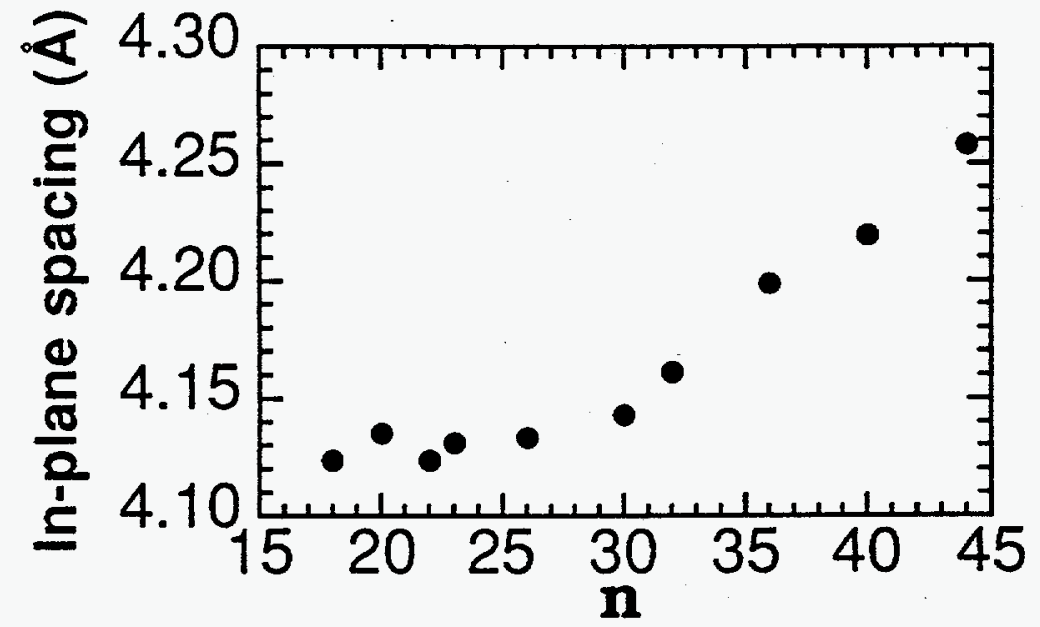

Fig. 5. The spacing $(2 \pi / \mathrm{q})$ of the in-plane, on axis (i.e. $\mathrm{q}_{\mathrm{z}}=0$ ) peak as a function of chain-length. (from Wu et al. ${ }^{28}$ )

\section{Liquid Surface : Surface Tension}

Surface tension measurements were performed to study the thermodynamics of the surface. ${ }^{26}$ In Fig. 6 , the surface tension measured for $\mathrm{C} 20$ and $\mathrm{C} 36$ are displayed. The surface tension is $\gamma=\varepsilon_{s}-\varepsilon_{B}-T\left(S_{S}-S_{B}\right)$ where $\varepsilon$ are the energies and $S$ are the entropies of a molecule on the surface or in the bulk, (according to the subscripts). The slope of $\gamma$ is then 
$d \gamma / d T=S_{B}-S_{S}=\Delta S$. In the liquid phase (L) there is the well-known ${ }^{1}$ behavior of a small negative slope implying greater freedom of surface molecules (i.e. $S_{S L}>S_{B L}$ ). The discontinuity in the slope ${ }^{40}$ at $T_{S}$ is the signature of a first-order surface transition to a phase where $d \gamma / d T>0$. Indeed, a molecule in the crystalline surface phase is more confined than one in the bulk liquid. Hence $S_{S R}<S_{B L}(L$ and $R$ denote liquid and rotator, respectively) and the slope becomes positive.

Since the structural results imply that the surface monolayer is of structure similar to that of a layer of the bulk rotator phase, the thermodynamics should be consistent as well. Assuming that $S_{S R}-S_{B R} \approx S S L-S_{B L}$, a comparison can be made between $\Delta S$ obtained from the surface tension slopes and $\Delta S$ from the bulk latent heat of the rotator-liquid transition ${ }^{1,8}$ (using the area/molecule to get moles per unit area). This is shown in Fig. 7. where the agreement is excellent, both in magnitude and in chain-length dependence.

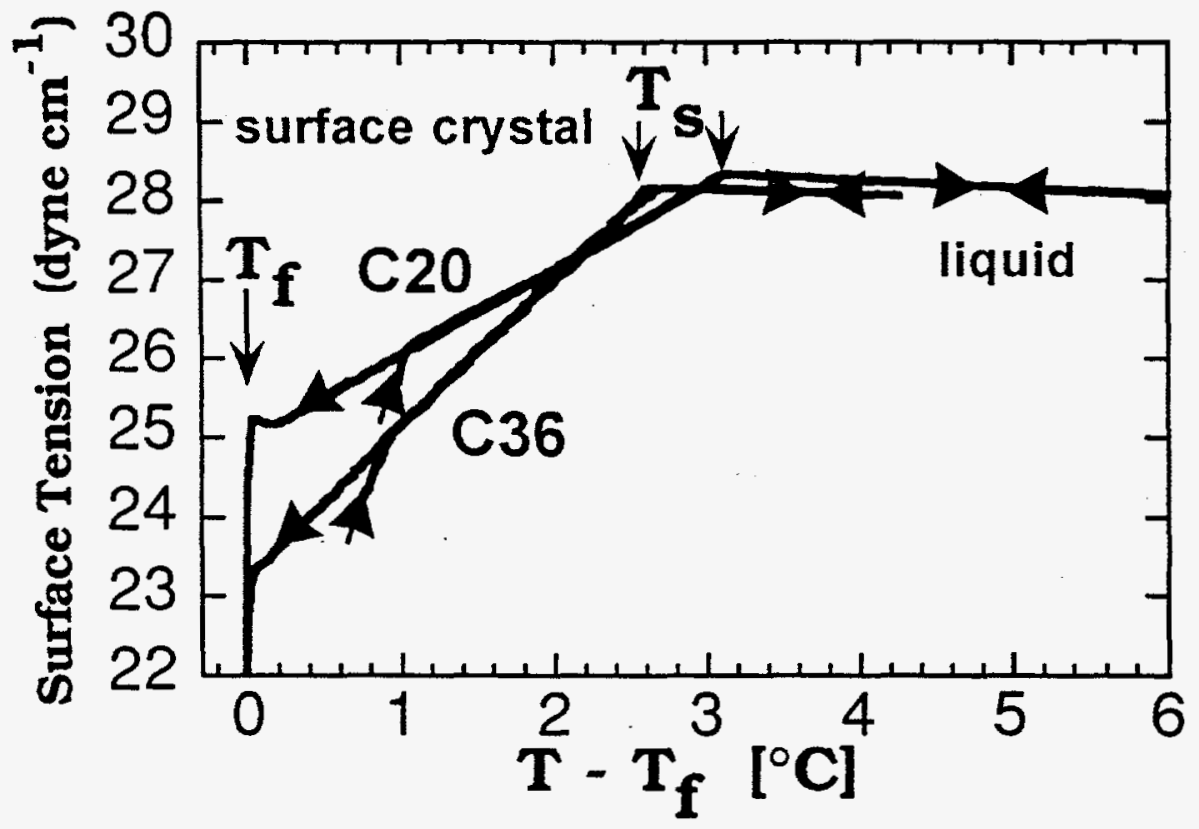

Fig. 6. The surface tensions ( $\gamma$ ) of $\mathrm{C} 20$ and $\mathrm{C} 36$ measured in cooling and heating cycles (as denoted by arrows). The temperature is plotted with respect to the bulk freezing temperature $T_{f}$. The slope change at $T_{s}$ indicates the formation of the monolayer. Note the larger slope for C36. (from Wu et al. ${ }^{26}$ )

The deviation in the figure for small $\mathrm{n}$ is probably related to the highest temperature bulk phase in that range. While the surface phase is $\mathrm{R}_{\mathrm{II}}$-like for all $\mathrm{n}$, the highest-temperature solid bulk phase for $n<21$ is $R_{I}$, so that in that range, the bulk melting is $R_{I}$-to-liquid. Thus, a comparison of the bulk melting $\Delta S$ for $n<21$ to that of the surface phase, where the melting is $\mathrm{R}_{\mathrm{II}}$-to-liquid like, may not be completely valid. The latent heat of the $\mathrm{R}_{\mathrm{I}}-\mathrm{R}_{\mathrm{II}}$ transition is strongly chain-length dependent, increasing from $0.25 \mathrm{~kJ} / \mathrm{mol}$ for $\mathrm{C} 25$ to $1.0 \mathrm{~kJ} / \mathrm{mol}$ for $\mathrm{C} 22 .^{8}$ Extrapolating to lower $n$, this could account for the deviation. 


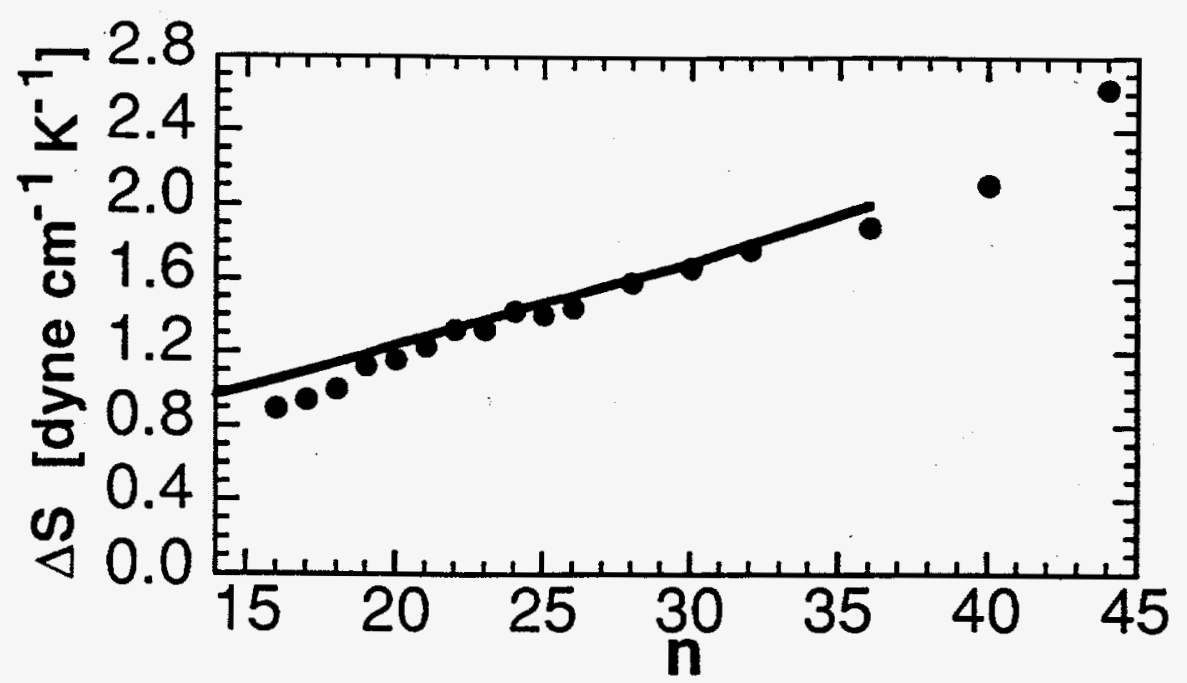

Fig. 7. $\Delta S$, the entropy change upon surface monolayer formation, as obtained from the slope difference of the surface tension at $T_{s}$ as a function of chain-length (dots) and the latent heat of the liquid-rotator melting transition per unit area (line). (surface tension data from $\mathrm{Wu}$ et al. ${ }^{26}$ )

Fig. 8 shows the temperature width of the surface-crystal phase as a function of chainlength. $\Delta T$ goes through zero at $n=14$. This can be interpreted as a crossover from the surface freezing behavior to the more common surface melting behavior. The solid line in the figure is a fit to a simple expression involving a $1 / \mathrm{d}^{2}$ Van der Waals interaction, discussed in detail elsewhere. ${ }^{26}$ The deviation at long chain-length is likely due to the increasing influence of intrachain disordering mechanisms as $\mathrm{n}$ increases.

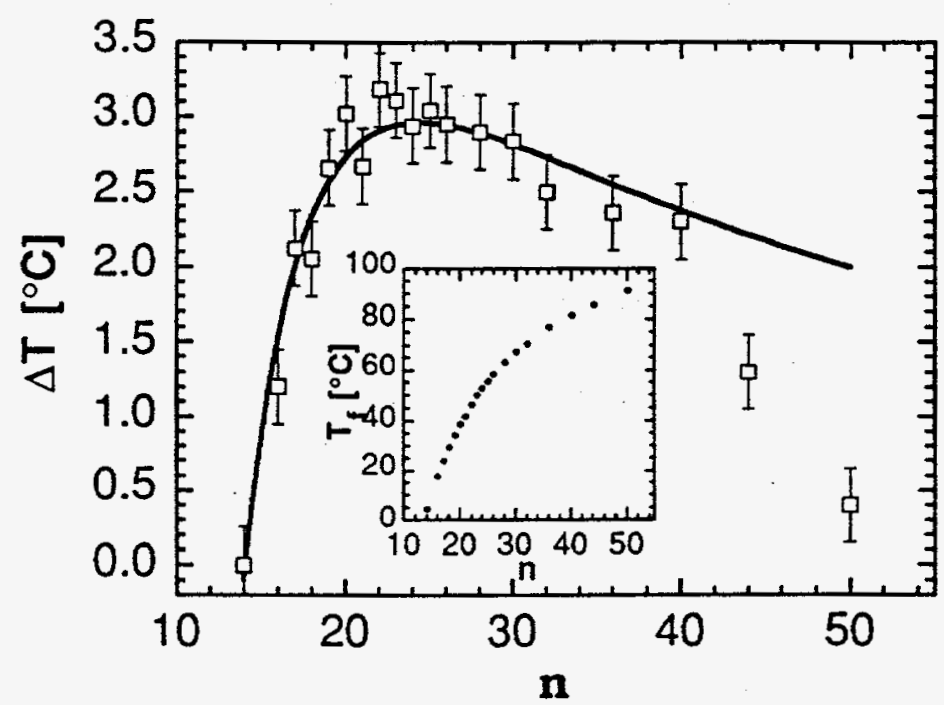

Fig. 8. The measured temperature width of the monolayer phase $\Delta T=T_{s}-T_{f}$ (squares) and a fit to the expression $\Delta \mathrm{T}=(\mathrm{a} / \mathrm{n})-\left(\mathrm{b} / \mathrm{n}^{3}\right)$ from Wu et al. ${ }^{26}$ Note the crossover to surface melting behavior for $\mathrm{n}<14$. (INSET) The bulk freezing temperature as a function of carbon number. (from Wu et al. ${ }^{26}$ ) 


\section{MELTING OF THIN FILMS}

Measurements were also performed on the melting of thin films of $\mathrm{C} 23$ on a $\mathrm{SiO}_{2}$ substrate. $^{33,34} \mathrm{C} 23$ films were prepared by evaporation of a dilute solution in hexane and annealing the films in the rotator phase, which produced aligned samples. ${ }^{7}$ Thicknesses and uniformities were measured using a variety of methods including, mass balance, optical microscopy, $x$-ray reflectivity and intensities and peak widths from $x$-ray scattering. The details of the sample preparation, and thickness determination are presented by Shao et al. ${ }^{34}$ The samples were studied using synchrotron X-ray scattering at Exxon's beamlines X10A\&B at the N.S.L.S.. Melting was determined with $x$-rays by the disappearance of both in-plane and layering peaks, as well as by changing textures as observed by optical microscopy. A schematic of the system is shown in Fig. 9. Since in this experiment, the structure of the layer of alkane in contact with the substrate was not investigated, in this discussion we will treat such a layer, if it is different from the interior layers as part of the interface between the interior of the film and the substrate.

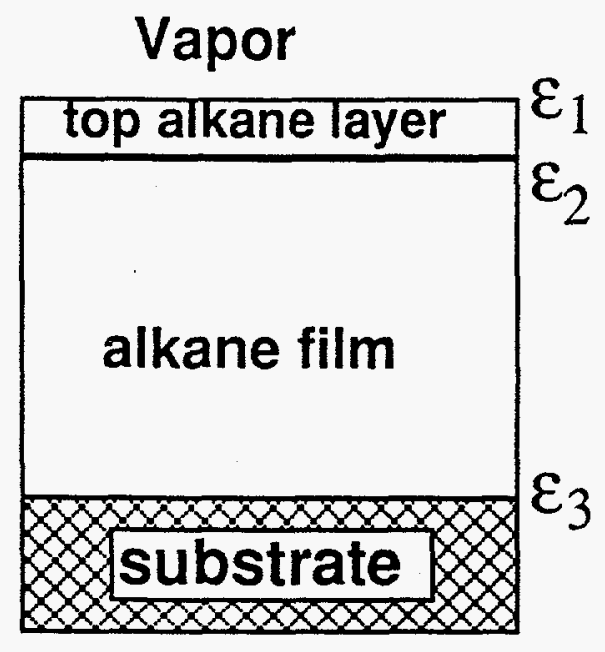

Fig. 9. Schematic of thin film.

The melting temperature of the interior of the film is shown in Fig. 10. Slightly above the melting temperature $\left(\sim 1^{\circ} \mathrm{C}\right)$ GIXS showed the presence of a surface crystallized monolayer, consistent with the structure observed on the bulk liquid-vapor interface by Wu et al. ${ }^{26}$ The films macroscopically beaded-up at temperatures more than $\sim 1^{\circ} \mathrm{C}$ above melting.

This system can be modeled by assuming that each layer of the alkane behaves as a layer of the bulk with a melting transition at $T_{\mathfrak{f}}$, a transition entropy of $\Delta S$ and an additional energy term if it is in contact with an interface. $F_{0}$ is the free energy per area of a $\mathrm{N}$ layer film which is entirely liquid. We let $\varepsilon_{1}$ be the free energy cost to have the top layer in the crystalline state $\left(\varepsilon_{1}<0\right)$. $\varepsilon_{2}$ is the energy cost for an alkane liquid-solid interface, as occurs when there is a surface crystalline layer on the liquid $\left(\varepsilon_{2}>0\right) . \varepsilon_{3}$ is the energy cost involved in having the alkane in contact with the 
$\mathrm{SiO}_{2}$ in the crystalline state $\left(\varepsilon_{3}>0\right)$. Thus, the free energy for an entirely crystalline film is $F_{c}=F_{0}+\varepsilon_{1}+\varepsilon_{3}+N \Delta S\left(T-T_{c}\right)$ and that for a liquid film with a crystalline layer at the vapor interface is $F_{S}=F_{0}+\varepsilon_{1}+\varepsilon_{2}+\Delta S\left(T-T_{c}\right)$. Using this simple model, the melting of the interior will occur when $F_{c}=F_{s}$. Thus, the melting temperature change in the thin films is given by $\Delta \mathrm{T}=-\left(\varepsilon_{3}-\varepsilon_{2}\right) / \Delta \mathrm{S}(\mathrm{N}-1)$ where $\mathrm{N}$ is the number of layers in the film. ${ }^{15}$ For $\mathrm{C} 23$, using the data in Fig. 10 and $\Delta S=1.37$ dyne $/(\mathrm{cm} \mathrm{K})^{1,26}$ we obtain $\varepsilon_{3}-\varepsilon_{2}=44$ dyne $/ \mathrm{cm}$.

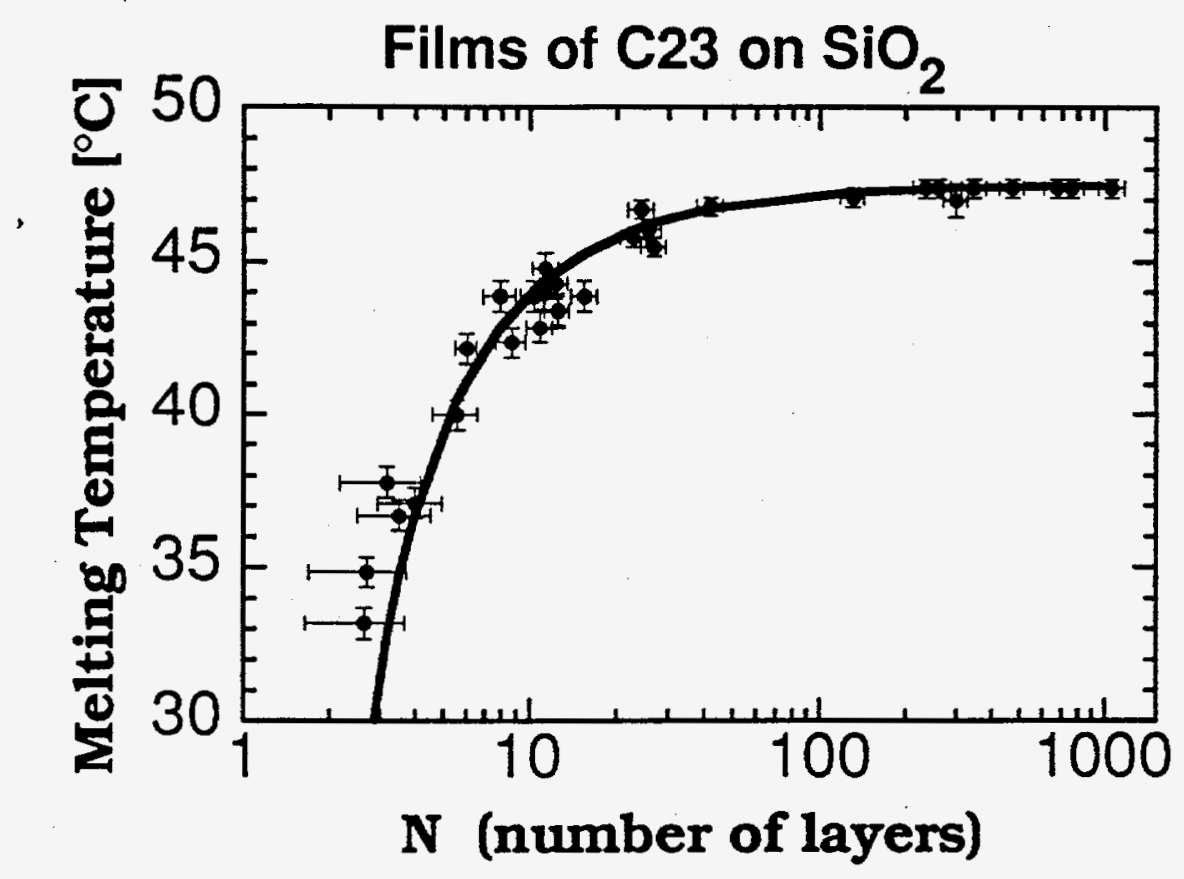

Fig. 10. Melting temperature of thin films of $\mathrm{C} 23$ on a $\mathrm{SiO}_{2}$ substrate. The uncertainties in $T$ and $N$ are shown. The line is a fit yielding $T_{m}=47.5-32 /(\mathrm{N}-1)$. (from Shao et al. ${ }^{33,34}$ )

The melting of the surface layer will occur when $F_{0}=F_{S}$ so the temperature range of the surface-crystal phase on the semi-infinite liquid is $\Delta T=-\left(\varepsilon_{1}+\varepsilon_{2}\right) / \Delta S$. For $\mathrm{C} 23$ this yields $\varepsilon_{1}+\varepsilon_{2}=-4.26$ dyne/cm using the measured $\Delta T$ shown in Fig. 8 . In order to independently determine $\varepsilon_{1}$ and $\varepsilon_{3}$ a third measurement would be needed. This could be either the melting temperature of the interior of freely suspended thin films where $\Delta T=\varepsilon_{2} / \Delta S(N-2)$, or the melting temperature of a film confined between 2 solid surfaces where $\Delta T=-\varepsilon_{3} /(\mathrm{N} \Delta \mathrm{S})$. The present numbers suggest, however, that the preference of the $\mathrm{SiO}_{2}$ interface for the liquid phase is much greater than the preference of the vapor interface for the rotator phase. This may be due to the preference for $\mathrm{CH}_{3}$ groups at the vapor interface and a preference for $\mathrm{CH}_{2}$ groups on the solid. with interaction energies much greater with the solid. To fully understand this, more detailed studies of the solid-liquid interface ${ }^{24}$ are required. 


\section{CONCLUSIONS}

Normal alkanes and their mixtures exhibit surface crystallization phenomena for chain lengths greater than 14 carbons. This phenomena has been explained with a simple thermodynamic model. The various structural properties are closely related to those of the bulk alkanes, but some unique features are also encountered. Thin films on a substrate exhibit a disordering phenomena. Such measurements can yield quantitative surface interaction energies. The rich bulk and surface properties of these simple normal alkanes will be important for understanding the properties of derivative chain molecules in bulk and on surfaces.

Related results showing new surface structures and phases have also been very recently observed in surface crystallization of pure 1-alcohols, ${ }^{41}$ binary mixtures of n-alkanes ${ }^{39}$ and on the thickess dependence of rotator phases in the thin films. ${ }^{34}$

We wish to acknowledge the technical assistance of D. M. Singer and B. Cao. This work was supported in part by The U.S.-Israel Binational Science Foundation, Jerusalem. Brookhaven National Laboratory is supported by the Division of Materials Research, U.S. Department of Energy under contract DE-AC02-76CH00016.

\section{REFERENCES}

1) D. M. Small, The Physical Chemistry of Lipids: From Alkanes to Phospholipids (Plenum, New York, 1986).

2) A. Müller, Proc. R. Soc. London, ser A 138, 514 (1932).

3) A. Craievich, J. Doucet, and I. Denicolo, Phys. Rev. B 32, 4164 (1985); A. Craievich, I. Denicolo, and J. Doucet, Phys. Rev. B 30, 4782 (1984); J. Doucet, I. Denicolo, A. F. Craievich, and C. Germain, J. Chem. Phys. 80, 1647 (1984); I. Denicolo, J. Doucet, and A. F. Craievich, J. Chem. Phys. 78, 1465 (1983); J. Doucet, I. Denicolo, and A. Craievich, J. Chem. Phys. 75, 1523 (1981); J. Doucet, I. Denicolo, A. Craievich, and A. Collet, J. Chem. Phys. 75, 5125 (1981).

4) G. Ungar and N. Masic, J. Phys. Chem. 89, 1036 (1985).

5) G. Ungar, J. Phys. Chem. 87, 689 (1983).

6) D. L. Dorset and H. Hu, Acta Cryst. A47, 543 (1991); D. L. Dorset, EMSA Bull. 20, 54 (1990); D. L. Dorset, B. Moss, J. C. Wittmann, and B. Lotz, Proc. Natl. Acad. Sci. 81, 1913 (1984).

7) E. B. Sirota, H. E. King Jr., D. M. Singer, and H. H. Shao, J. Chem. Phys. 98, 5809 (1993).

8) E. B. Sirota and D. M. Singer, J. Chem. Phys. 101, 10873 (1994).

9) E. B. Sirota, H. E. King Jr., H. H. Shao, and D. M. Singer, J. Phys. Chem. January (1995). 
10) E. B. Sirota, H. E. King Jr., G. J. Hughes, and W. K. Wan, Phys. Rev. Lett. 68, 492 (1992).

11) E. B. Sirota, D. M. Singer, and H. E. King Jr., J. Chem. Phys. 100, 1542 (1994).

12) J. G. Dash, Contemp. Phys. 30,89 (1989).

13) R. Lipowsky, J. Appl. Phys. 55, 2485 (1984).

14) D. E. Moncton, R. Pindak, S. C. Davey, and G. S. Brown, Phys. Rev. Lett. 49, 1865 (1982).

15) E. B. Sirota, P. S. Pershan, L. B. Sorensen, and J. Collett, Phys, Rev. A 36, 2890 (1987).

16) D. Y. Noh, J. D. Brock, J. O. Fossum, J. P. Hill, W. J. Nuttall, J. D. Litster, and R. J. Birgeneau, Phys. Rev. B 43, 842 (1991).

17) R. Geer, T. Stoebe, and C. C. Huang, (1994).

18) E. B. Sirota, P. S. Pershan, S. Amador, and L. B. Sorensen, Phys. Rev. A 35, 2283 (1987).

19) B. S. Swanson, H. Stragier, D. J. Tweet, and L. B. Sorensen, Phys. Rev. Lett. 62, 909 (1989).

20) J. Als-Nielsen, F. Christensen, and P. S. Pershan, Phys. Rev. Lett. 48, 1107 (1982).

21) B. M. Ocko, A. Braslau, P. S. Pershan, J. Als-Nielsen, and M. Deutsch, Phys. Rev. Lett. 57, 94 (1986).

22) P. S. Pershan, A. Braslau, A. H. Weiss, and J. Als-Nielsen, Phys. Rev. A 35, 4800 (1987).

23) G. J. Kellog, P. S. Pershan, E. H. Kawamoto, W. Foster, M. Deutsch, and B. M. Ocko, Phys. Rev. E (submitted).

24) B. M. Ocko, Phys. Rev. Lett. 64, 2160 (1990).

25) X. Z. Wu, E. B. Sirota, S. K. Sinha, B. M. Ocko, and M. Deutsch, Phys. Rev. Lett. 70, 958 (1993).

26) X. Z. Wu, B. M. Ocko, E. B. Sirota, S. K. Sinha, M. Deutsch, B. H. Cao, and M. W. Kim, Science 261, 1018 (1993).

27) X. Z. Wu, E. B. Sirota, B. M. Ocko, S. K. Sinha, M. Deutsch, and M. W. Kim, (to be published).

28) X. Z. Wu, B. M. Ocko, E. B. Sirota, S. K. Sinha, and M. Deutsch, Physica A 200, 751 (1993).

29) A. Braslau, M. Deutsch, P. S. Pershan, A. H. Weiss, J. Als-Nielsen, and J. Bohr, Phys. Rev. Lett. 54, 114 (1985).

30) A. Braslau, P. S. Pershan, G. Swislow, B. M. Ocko, and J. Als-Nielsen, Phys. Rev. A 38, 2457 (1988).

31) M. K. Sanyal, S. K. Sinha, K. G. Huang, and B. M. Ocko, Phys. Rev. Lett. 66, 628 (1991).

32) B. M. Ocko, X. Z. Wu, E. B. Sirota, S. K. Sinha, and M. Deutsch, Phys. Rev. Lett. 72, 242 (1994).

33) H. Shao, H. E. King Jr., E. B. Sirota, and D. M. Singer, Bull. A.P.S. 38, 535 (1993). 
34) H. Shao, H. E. King Jr., D. M. Singer, and E. B. Sirota, (to be published).

35) M. Maroncelli, H. L. Strauss, and R. G. Snyder, J. Chem. Phys. 82, 2811 (1985).

36) W. L. Jarrett, L. J. Mathias, R. G. Alamo, L. Mandelkern, and D. L. Dorset, Macromolecules 25, 3468 (1992).

37) E. B. Sirota, J. Phys. (Paris) 49, 1443 (1988).

38) E. B. Sirota, C. R. Safinya, G. S. Smith, R. Plano, D. Roux, and N. A. Clark, in Geometry and Thermodynamics, edited by J. C. Toledano (Plenum, New York, 1990), p. 255.

39) X. Z. Wu, M. Deutsch, B. M. Ocko, H. Tang, E. B. Sirota, and S. K. Sinha, (to be published).

40) J. C. Earnshaw and C. J. Hughes, Phys. Rev. A 46, R4494 (1992).

41) M. Deutsch, X. Z. Wu, E. B. Sirota, S. K. Sinha, B. M. Ocko, and O. M. Magnussen, Europhys. Lett. (submitted).

\section{DISCLAIMER}

This report was prepared as an account of work sponsored by an agency of the United States Government. Neither the United States Government nor any agency thereof, nor any of their employees, makes any warranty, express or implied, or assumes any legal liability or responsibility for the accuracy, completeness, or usefulness of any information, apparatus, product, or process disclosed, or represents that its use would not infringe privately owned rights. Reference herein to any specific commercial product, process, or service by trade name, trademark, manufacturer, or otherwise does not necessarily constitute or imply its endorsement, recommendation, or favoring by the United States Government or any agency thereof. The views and opinions of authors expressed herein do not necessarily state or reflect those of the United States Government or any agency thereof. 